\title{
Effects of standardized medicinal plant extracts on drug metabolism mediated by CYP3A4 and CYP2D6 enzymes
}

Clarissa Feltrin †; Ingrid Vicente Farias †; Louis Pergaud Sandjo ‡; Flávio Henrique Reginatto $^{\dagger}$; Cláudia Maria Oliveira Simões ${ }^{\dagger *}$

† Programa de Pós-Graduação em Farmácia, Centro de Ciências da Saúde, Universidade Federal de Santa Catarina, Florianópolis, Santa Catarina, Brazil.

‡ Departamento de Química, Universidade Federal de Santa Catarina, Florianópolis, Santa Catarina, Brazil.

*Corresponding author: Cláudia Maria Oliveira Simões, claudia.simoes@ufsc.br. Phone: +55 -48 3721 3499. Address: Programa de Pós-Graduação em Farmácia, Centro de Ciências da Saúde, Universidade Federal de Santa Catarina, Campus Reitor João David Ferreira Lima, Rua Delfino Conti, s/n, Trindade, Florianópolis, Santa Catarina, Brazil, CEP: 88040-900.

\section{RESULTS}

1.1 Characterization of drug substrates and their metabolites

Table S1: Parameters obtained for the validation of the analytical methods.

\begin{tabular}{|c|c|c|c|}
\hline & Concentration $(\boldsymbol{\mu M})$ & Precision (RSD \%) & Accuracy (\%)* \\
\hline OH-midazolam & 1 & 11.5 & $84.1-117.1$ \\
& 2.5 & 12.4 & $82.5-116.6$ \\
& 5 & 9.0 & $88.8-116.3$ \\
\hline OH-metoprolol & 6.25 & 9.5 & $91.7-110.3$ \\
& 50 & 1.2 & $99.0-101.4$ \\
& 80 & 12.4 & $85.7-107.5$ \\
\hline 0-demethylmetoprolol & 6.25 & 11.2 & $88.5-110.8$ \\
& 50 & 10.8 & $89.2-110.7$ \\
& 80 & 13.2 & $88.5-114.5$ \\
\hline
\end{tabular}

*The data correspond to three independent analyses.

RSD: Relative Standard Deviation 
Midazolam

A
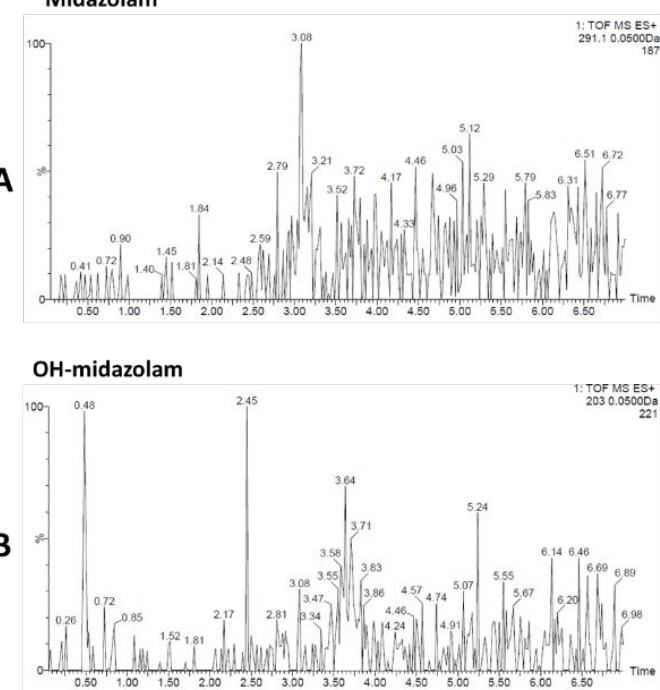

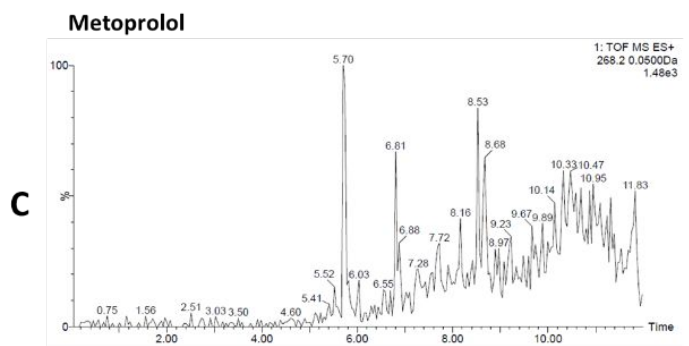

O-demethylmetoprolo
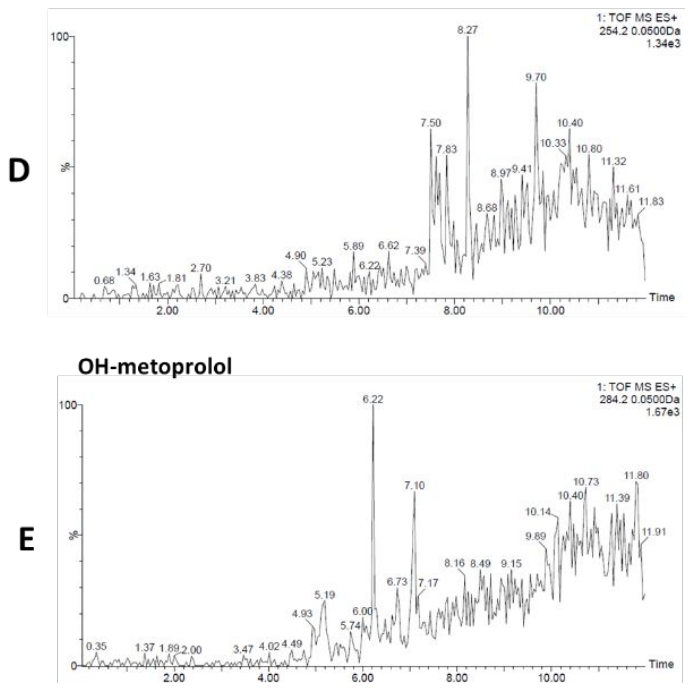

Figure S1: Specificity of the chromatographic method - Blank of the reaction mix. A. midazolam, B. OHmidazolam, C. metoprolol, D. $\mathrm{O}$-demethylmetoprolol, E. OH-metoprolol. 
1.2 Identification of the major phytoconstituents of Cecropia glaziovii and Ilex paraguariensis by UPLC-MS/MS
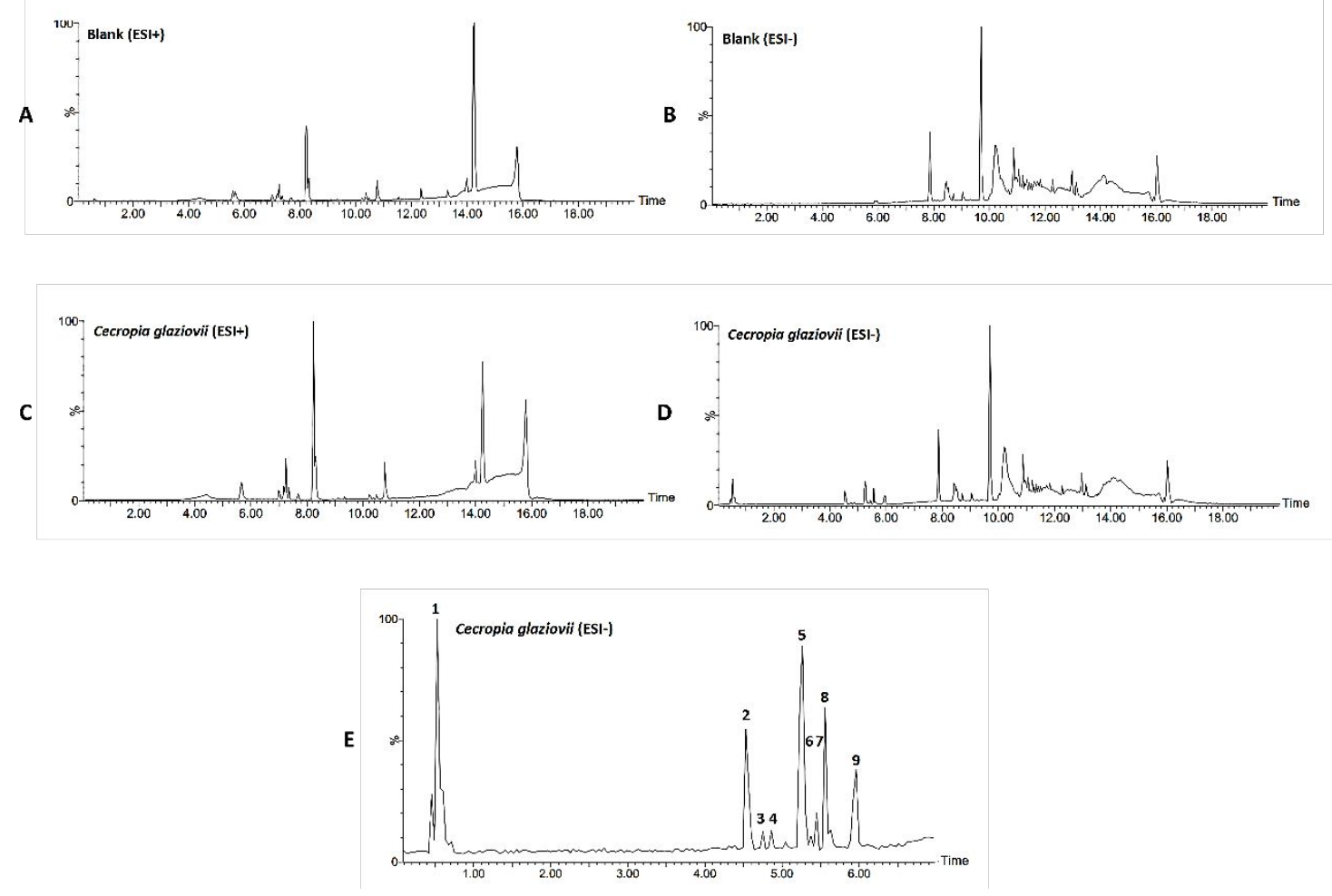

Figure S2: A. ESI+ and B. ESI-: solvent chromatograms; C. ESI+ and D. ESI-: complete chromatograms of Cecropia glaziovii; E. ESI-: chromatogram with numerical indications of peaks corresponding to the major compounds identified in C. glaziovii extract; all obtained by UHPLC-MS/MS. The identification of each numbered peak can be seen in Table 3 of the manuscript. 

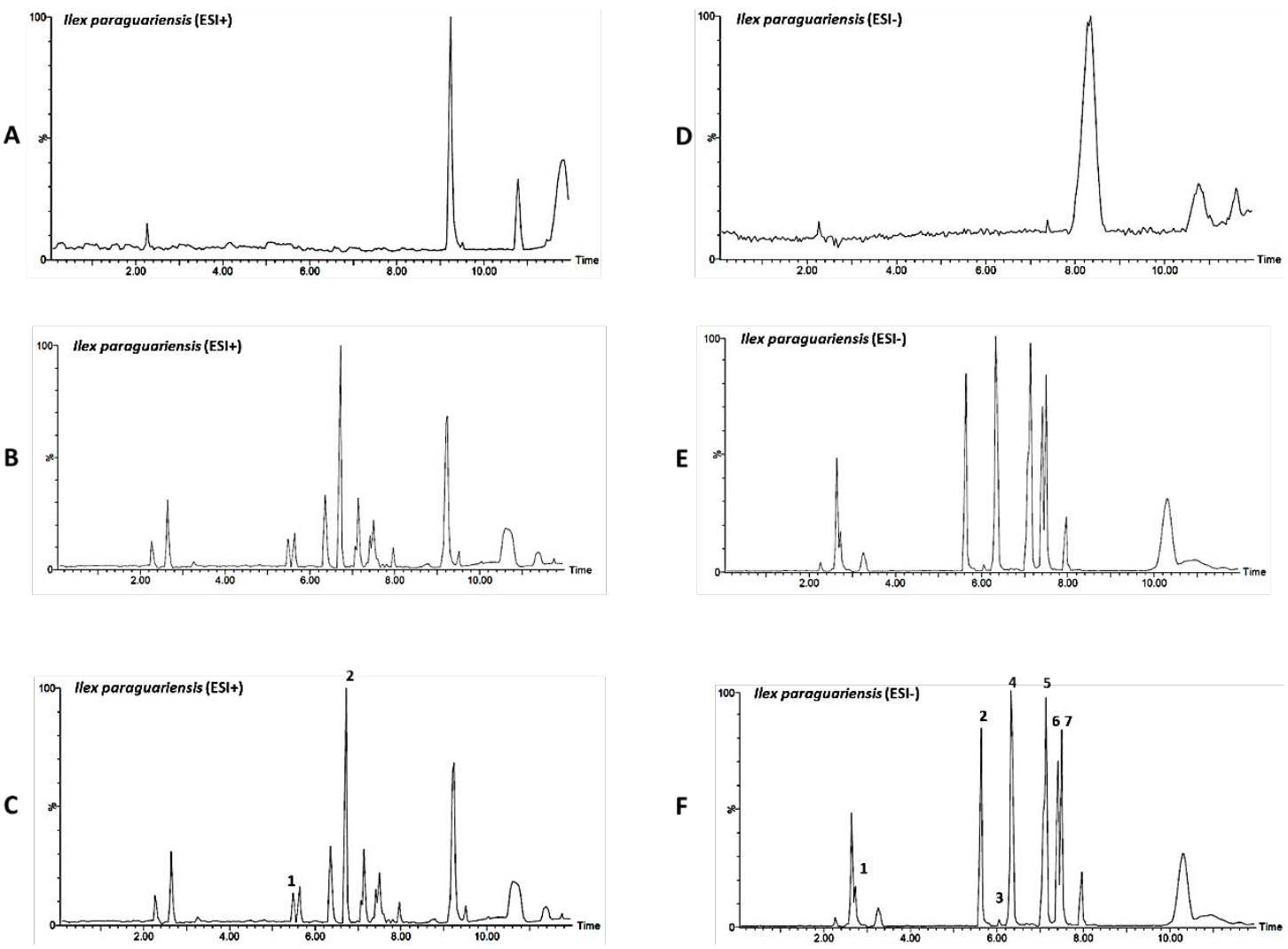

Figure S3: A. ESI+ and D. ESI -: solvent chromatograms; B. ESI+ and E. ESI-: complete chromatograms of Ilex paraguariensis; $\mathbf{C}$. ESI+ and F. ESI-: chromatograms with numerical indications of peaks corresponding to the major compounds identified in the I. paraguariensis extract; all obtained by UHPLC-MS/MS. The identification of each numbered peak can be seen in Table 4 of the manuscript. 